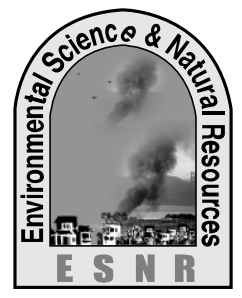

J. Environ. Sci. \& Natural Resources, 6(1): 33 - 36, 2013

ISSN 1999-7361

\title{
Multivariate Analysis Approach to Select Parents for Hybridization Aiming at Yield Improvement in Cucumber (Cucumis sativus L.)
}

\author{
S. Afroz ${ }^{1}$, M. S. Noman, ${ }^{*}$ M. S. Hossain ${ }^{2}$ A. A. Mamun, ${ }^{3}$ N. Howlader ${ }^{4}$ and S. Ara ${ }^{1}$ \\ ${ }^{1}$ Department of Agricultural Extension, Dumki, Patuakhali, Bangladesh, \\ *On-Farm Research Division, BARI, Bogra \\ .$^{2}$ Departments of Genetics and Plant Breeding, Sher-e-Bangla Agricultural University, Dhaka, \\ Bangladesh. \\ ${ }^{3}$ Agrotechnology Discipline, Khulna University, Bangladesh , \\ ${ }^{4}$ Syngenta Bangladesh Limited, Bangladesh, ${ }^{5}$ Agriculture Training Institute, Faridpur, Bangladesh
}

\begin{abstract}
Twenty two genotypes of cucumber (Cucumis sativus L.) were evaluated using $\mathrm{D}^{2}$ and principal component analysis (PCA). The genotypes were collected from Plant Genetic Resources Centre (PGRC) of Bangladesh Agricultural Research Institute (BARI), Gazipur, Agro-G, \& Lal Teer seed company. The study was undertaken at Sher-e-Bangla Agricultural University Farm, Dhaka during March 2010 to October 2010 to select suitable donor parents for improved breeding of cucumber. Principal component analysis (PCA) revealed that the first two axes accounted for $67.39 \%$ of the total variation among the fourteen characters studied. As per cluster analysis, the genotypes were grouped into four clusters consisting 5, 3, 8 and 6 genotypes which revealed that there exist considerable diversity among the genotypes. Highest intra-cluster distance was found in cluster $\Pi 1$ and lowest in cluster IV. Among four clusters, the highest inter-cluster distance was observed between cluster II and cluster $\amalg$ and lowest between cluster I and cluster IV. Considering all of the characters studied, the Serena, BD-4305, BD-4256, CU937F1 and BD-4309 were selected for future breeding programme.
\end{abstract}

Key words: Cucumber (Cucumis sativus L.), genetic variability, parents, hybridization.

\section{Introduction}

Cucumber (Cucumis sativus L.) is an important home garden vegetable and widely cultivated as a popular winter vegetable in Bangladesh as well as many countries of the world. It is a vigorous, annual, climbing vine and a lush appearance. They are botanically categorized as berries, which are available in many different sizes, shapes and colors. It is one of the most popular fruit vegetables and salad crops in Bangladesh. It is grown round the year and seems to be a day neutral crop. There are about 1.02 million hectare of land under cultivation and production is about 1.61 million tons (Anonymous, 2007) with high price potential round the year making cucumber a high value crop. The average yield of cucumber is about 1200 to $1400 \mathrm{~kg}$ per hectare. There are several cultivars of cucumber which are traditionally cultivated in our country but there is no recommended variety. Farmers cultivate the cucumber from their own seeds. Therefore, it is necessary to develop superior varieties of cucumber for commercial cultivation in our country. So, improvement of the crop is urgent now for our agriculture. Hybridization is one of the major tools for achieving variability aiming at the improvement of a crop. Genetic diversity is a useful tool in quantifying the degree of divergence in a biological population at genotypic level and to assess relative contribution of different components to the total divergence both at intra and inter-cluster levels (Jatasra and Paroda, 1978). Cluster analysis is also carried out to detect divergent parents for hybridization purposes and to attain meaningful group constellations of a collection of genotypes. Considering the availability of genetic variability, its scope of yield improvement and export potential, the present investigation was undertaken to search suitable diverse germplasm as suitable parents for future breeding program of cucumber.

\section{Materials and Methods}

A total of twenty two genotypes of cucumber, collected from Plant Genetic Resources Centre (PGRC) of Bangladesh Agricultural Research Institute (BARI), Gazipur, Agro-G, \& Lal Teer seed company namely: BD 4207(1), BD 4234(2), BD 4244(3), BD 4249(4), BD 4251(5), BD 4256(6), BD 4305(7), BD 4308(8), BD 4309(9), BD 4313(10), BD 4315(11), BD 4320(12), Chamok 34(13), Serena(14), Alavy(15), Sishir(16), CU 937 (17), Joti (18), Mukta (19), Green joint(20), Baromashi (21) and Local (22), were grown at the farm of Sher-e-Bangla Agricultural University, Dhaka following randomized block design with three replications during March-Oct. 2011. Each replication consisted of 20 pits. The spacing pit to pit and block to block was 1.5 and 0.6 $\mathrm{m}$, respectively. Data were recorded for leaf length (LL), leaf breadth (LB), leaf petiole length (LPL), number of branches per vine (NB), days to first male flowering (DMF), days to first female flowering (DFF), number of male flowers per plant (MFP), number of female flowers per plant (FFP), number of fruits per plant (FP), weight of fruit (WF), length of fruit (LF), breadth of fruit (BF), length of peduncle 
(LP) and fruit yield per plant (FYP). Data were subjected to both univariate and multivariate analysis. Under multivariate analysis Principal Component Analysis (PCO), Principal Coordinate Analysis (PCA), Cluster Analysis (CA) and Canonical Vector Analysis were done by using GENSTAT 5.5 program.

\section{Results and Discussion}

Analysis of variance showed significant variations among the tested genotypes for all the characters studied indicating a wide genotypic variation among the genotypes. The principal component analysis produced eigen values of principal component axes for coordination of genotypes in which the first two axes accounted for $67.39 \%$ of the total variation. On the basis of principal axes I and II, a two dimension chart $\left(Z_{1}-Z_{2}\right)$ of the genotypes are presented in Fig. 1.
As per the scattered diagram the genotypes were apparently distributed into four clusters.

Using co-variance matrix with the application of nonhierarchical clustering, the 22 cucumber genotypes were grouped into four clusters. Gaffar (2008) reported similar number of clustering in 15 sponge gourd genotypes. Quamruzzaman et al. (2008) reported four clusters, Badade et al. (2001) ten clusters in bottle gourd. The clustering pattern is determined by the principal component analysis (Table 1) which represents the composition of different clusters with the genotypes. The distribution pattern indicated that the maximum genotypes (8) was included in cluster III followed by cluster IV (6), cluster I (5) and cluster II (3). Genotypes in four clusters ranged from 8 to 3 . The distribution of genotypes into four clusters revealed that there exists considerable diversity among the genotypes.

Table 1. Distribution of twenty two cucumber (Cucumis sativus L.) genotypes in four clusters

\begin{tabular}{c|c|l}
\hline Cluster & Numbers & \multicolumn{1}{c}{ Name of the Genotypes } \\
\hline I & 5 & BD 4249, BD 4313, Joti, Green joint, Baromashi \\
II & 3 & BD 4305, Mukta, Local \\
III & 8 & $\begin{array}{l}\text { BD 4207, BD 4234, BD 4309, Chamok 34, Serena, Alavy, } \\
\text { Sishir, CU 937 F1 }\end{array}$ \\
IV & 6 & $\begin{array}{l}\text { BD 4244, BD 4251, BD 4256, BD 4308, BD 4315, BD } \\
\text { 4320 }\end{array}$ \\
\hline
\end{tabular}

Intra-cluster distances were estimated using the inter genotypic distance (Table 2) following by Singh and Chaudhury (1977). The highest intra-cluster distance was recorded in cluster III (1.284) containing highest (8) genotypes followed by cluster I (1.201) with five genotypes. The lowest intra-cluster distance was observed in cluster IV (0.707) having six genotypes. It was favored to decide that intra-cluster diversity was the highest in cluster III i.e., more heterogeneous and intra-cluster diversity was lower in cluster IV i.e. comparatively homogenous.

The highest inter-cluster distance was observed between cluster II and cluster III (27.666) followed by between cluster II and cluster IV (20.099) and between cluster I and cluster III (14.158). The higher inter-cluster distances between these clusters indicate to obtain wide spectrum of segregating population if parents chosen from these distant clusters are used for hybridization program. However, the highest intercluster distance was observed between clusters II and III indicated the genotypes in these clusters were far diverged than those of other clusters. Similarly, the lowest inter-cluster distance was observed between the cluster I and IV (6.865). Moderate or intermediate distance was found between cluster I and II (13.514). The inter cluster distances were found much higher than the intra cluster distances suggesting wider genetic diversity existed among the genotype of different groups. Quamrzzaman et al. (2008) obtained longer inter-cluster distances than the intra-cluster distances in a multivariate analysis.

Table 2. Average intra- and inter-cluster distances of twenty two cucumber (Cucumis sativus L.) genotypes

\begin{tabular}{ccccc}
\hline & I & II & III & IV \\
\hline I & $\mathbf{1 . 2 0 1}$ & & & \\
II & 13.514 & $\mathbf{1 . 0 3 6}$ & & \\
III & 14.158 & 27.666 & $\mathbf{1 . 2 8 4}$ & \\
IV & 6.865 & 20.099 & 8.241 & $\mathbf{0 . 7 0 7}$ \\
\hline
\end{tabular}


Higher inter and intra-cluster distances indicated higher genetic variability among genotypes between and within clusters, respectively. The minimum inter and intra-cluster distance indicated closeness among the genotypes of two clusters and within the cluster also. These relationships were also reflected in the scatter diagram (Fig. 1). Islam et al. (2004) also observed the similar results.

It is assumed that maximum amount of heterosis will be manifested in cross combination involving the genotypes belonging to most divergent clusters. However, for a practical plant breeding, the objective is not only high heterosis but also to achieved highlevel production. In the present study the maximum distance exists between cluster II and III. But considering the yield and duration, crosses involving cluster II and III may be exhibit high heterosis for yield. Main and Bahl (1989) reported that the parents separated by $\mathrm{D}^{2}$ values of moderate magnitude generally showed higher heterosis.

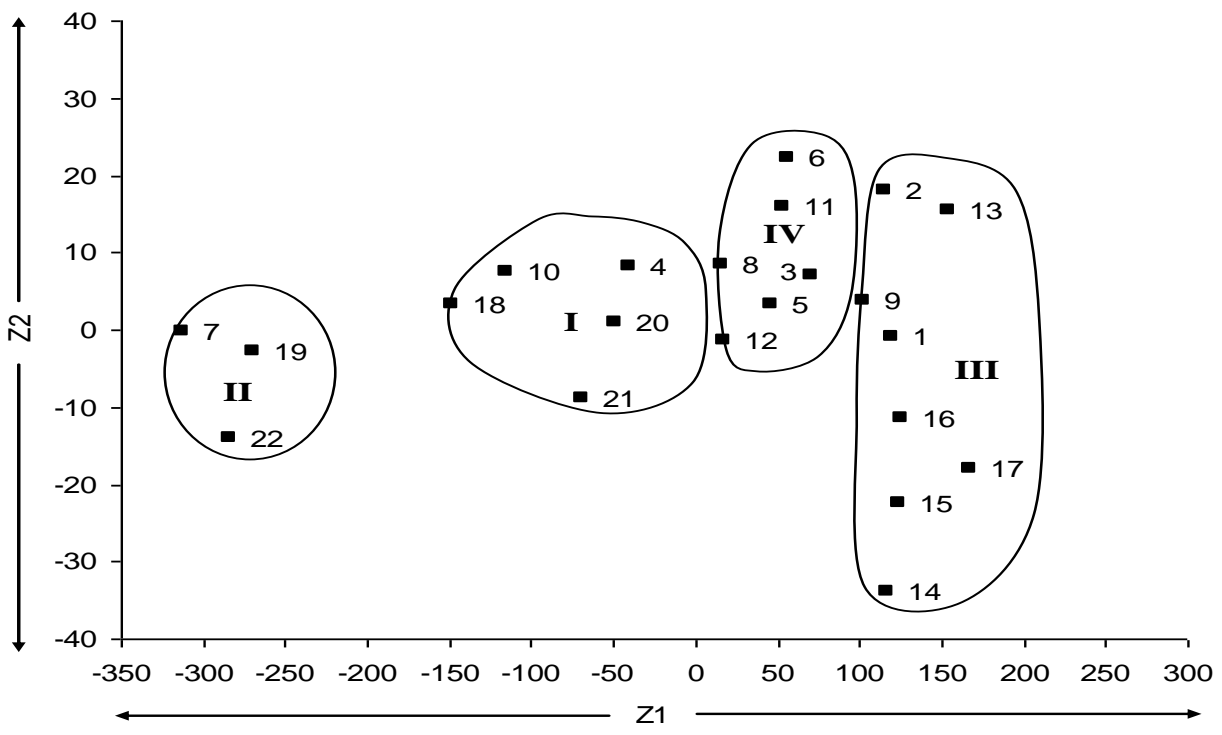

Fig. 1. Scattered diagram of twenty two cucumber genotypes superimpose cluster.

From distant matrix of Principal Coordinate Analysis 10 most distant pairs and 10 lower pair of genotypes were selected (Table 3). The highest inter genotypic distance was observed between genotypes BD 4305 and Chamak 34 (2.333) followed by Chamak 34 and Joti (2.309) and the lowest distance was observed (0.359) between genotypes Green joint and Baromashi followed by the distance $(0.556)$ between genotypes BD 4244 and BD 4251. The difference between the highest and the lowest inter genotypic distance indicated the moderate variability among the 22 genotypes of cucumber. Chauhan and Singh (1982) reported maximum heterosis observed in those crosses, which were involved moderately diverged parents.

Buu and Tuan (1989) and Joshi and Dhawan (1966) reported that genetic diversity is very much important factor for any hybridization program aiming at genetic improvement of yield. Bhatt (1970) inferred that Mahalanobis's $\mathrm{D}^{2}$ statistic was a powerful tool as a method of choosing parents for hybridization aiming at hybrid improvement. Findings of the present study indicated significant variation among the genotypes for all the characters studied. Considering diversity pattern and other field performances, the genotypes Serena from cluster III; BD-4305 from cluster II; BD-4309 and CU937F1 from cluster III, and BD-4256 from cluster IV could be best choice as suitable parents for efficient hybridization programme. The inter genotypic crosses between Serena and BD-4305; Serena and BD-4256; Serena and BD-4309; BD-4305 and CU937F1; BD4305 and BD-4256; BD-4305 and BD-4309 might be suitable choice for future hybridization programme. 
Table 3. Ten highest and ten lowest inter genotypic distance among the twenty two cucumber genotypes

\begin{tabular}{|c|c|c|}
\hline Sl. & Genotypic & Distances \\
No. & combination & \\
\hline
\end{tabular}

A. ten highest inter genotypic distance

\begin{tabular}{|c|l|l|}
\hline 1 & Chamok 34 - BD 4305 & 2.333 \\
\hline 2 & Joti - Chamok 34 & 2.309 \\
\hline 3 & Baromashi - BD 4309 & 2.139 \\
\hline 4 & Local - Sishir & 2.105 \\
\hline 5 & Alavy - BD 4249 & 2.055 \\
\hline 6 & Green joint - BD 4309 & 2.044 \\
\hline 7 & Local - BD 4313 & 2.042 \\
\hline 8 & Sishir - BD 4249 & 2.028 \\
\hline 9 & CU 937 F1 - BD 4305 & 1.997 \\
\hline 10 & Baromashi - Joti & 1.995 \\
\hline
\end{tabular}

B. ten lowest inter genotypic distance

\begin{tabular}{|c|l|l|}
\hline 1 & Baromashi - Green joint & 0.359 \\
\hline 2 & BD 4251 - BD4244 & 0.556 \\
\hline 3 & BD 4256 - BD 4251 & 0.591 \\
\hline 4 & Green joint - BD 4315 & 0.602 \\
\hline 5 & Mukta - BD 4313 & 0.635 \\
\hline 6 & BD 4315 - BD4244 & 0.656 \\
\hline 7 & BD 4308 - BD 4251 & 0.657 \\
\hline 8 & BD 4308 - BD 4234 & 0.673 \\
\hline 9 & Green joint - BD 4251 & 0.680 \\
\hline 10 & BD 4308 - BD 4256 & 0.691 \\
\hline
\end{tabular}

\section{Conclusion}

Considering diversity pattern and other field performances, the genotypes Serena from cluster III; BD-4305 from cluster II; BD-4309 and CU937F1 from cluster III, and BD-4256 from cluster IV could be best choice as suitable parents for efficient hybridization program. The inter genotypic crosses between Serena and BD-4305; Serena and BD-4256; Serena and BD-4309; BD-4305 and CU937F1; BD4305 and BD-4256; BD-4305 and BD-4309 might be suitable choice for future hybridization program.

\section{References}

Anonymous. 2007. Advanced yield trial of cucumber. Annual Research Report on Horticulture Research Center. Bangladesh Agricultural Research Institute. P. 45.

Jatasara, D. S. and Paroda, R. S. 1978. Genetic divergence in Wheat under different environmental conditions. Cereal Res. Comm., 6: 307-317.

Gaffar, A. 2008. Characterization and genetic diversity of sponge gourd (Luffa cylindrica L.). MS Thesis. Dept. Genet. and Plant Breed., Sher-e-Bangla Agricultural University, Dhaka.

Quamruzzaman, A. K. M.; Rahman, M. H.; Islam, M. N.; Rahman, S. M. L. and Sarker, B. C. 2008. Genetic diversity in land races of ridge gourd. Bangladesh Res. Pub. J., 1 (1): 5-12.

Badade, D. S.; Warade, S. D. and Gaikwad, S. K. 2001. Genetic divergence in Bottle gourd. $J$. Maharashtra Agril. Univ., 26 (2): 137-139.

Singh, S. K. and Chaudhury, B. D. 1977. Biometrical methods in quantitative genetic analysis. Kalyani publishers, New Delhi. pp. 215-238.

Islam, M. R.; Faruquei, M. A. B.; Bhuiyan, M. A. R.; Biswas, P. S. and Salam, M. A. 2004. Genetic diversity in irrigated rice. Pak. J. Biol. Sci., 7(2): 226-229.

Main, M. A. K. and Bahl, P. N. 1989. Genetic divergence and hybrid performance in chickpea. Indian J. Genet. 49: 119-124.

Chauhan, V. S. and Singh, B. B. 1982. Heterosis and genetic variability in relation to genetic divergence in soybean. Indian J. Genet. Pl. Breed. 42(2): 324-328.

Buu, B. C. and Tuan, T. M. 1989. Genetic diversity in rice (Oryza sativa L.). Intl. Rice Res. Newsl.14: 6.

Joshi, A. B. and Dhawan, N. L. 1966. Genetic improvement of yield with special reference to self-fertilizing crops. Indian J. Genet. Pl. Breed. 26A: 101-113.

Bhatt, G. M. 1970. Multivariate analysis approach to selection of parents of hybridization aiming at yield improvement in self-pollinated crops. Aust. J. Agric. Res., 21: 1-7. 